\title{
Comparison of Ceftriaxone and Cefazolin Sodium Antibiotic Prophylaxis in Terms of SIRS/Urosepsis Rates in Patients Undergoing Percutaneous Nephrolithotomy
}

\author{
Perkütan Nefrolitotomi Ameliyatı Olan Hastalara Verilen Seftriakson ve Sefazolin Sodyum \\ Antibiyotik Profilaksilerinin SIRS/Ürosepsis Oranları Açısından Karşılaştırılması
}

\author{
(D) Kerem Taken1, (D) Alper Aşık1 , (D) Recep Eryılmaz1, (D) Rahmi Aslan11, (D) Muhammet İrfan Dönmez², (D) Mustafa Güneş¹ \\ 1 Yüzüncü Yıl University Faculty of Medicine, Department of Urology, Van, Turkiye \\ 2Konya Training and Research Hospital, Clinic of Urology, Konya, Turkiye
}

\section{What's known on the subject? and What does the study add?}

Percutaneous nephrolithotomy have infectious complications in the form of systemic inflammatory response (SIRS) and urosepsis. Antibiotic prophylaxis in order to prevent this complication has been widely investigated. Our prospective randomized study highlights two commonly used antibiotics in Turkiye and their effects on infectious complications. Our results indicate similar SIRS/urosepsis rates between groups and hence we advise to use cefazolin that has a narrower anti-bacterial spectrum.

\begin{abstract}
Objective: The aim of this study is to compare ceftriaxone and cefazoline sodium antibiotic prophylaxis in terms of development of Systemic Inflammatory Response syndrome (SIRS)/urosepsis in patients undergoing percutaneous nephrolithotomy (PCNL).

Materials and Methods: Patients who underwent PCNL between June 2015 and October 2015 in our hospital were prospectively randomized to ceftriaxone $(n=30)$ and cefazoline sodium $(n=32)$ antibiotic prophylaxis groups. Patients with predisposing conditions to SIRS were excluded. Intraoperative urine cultures from renal pelvis and stone cultures were obtained from all patients. Clinical and laboratory findings of the patients who developed postoperative fever were evaluated. SIRS and urosepsis rates were compared between two groups.

Results: There were 7 patients in ceftriaxone group (23.3\%) and 4 patients in cefazoline sodium group (12.5\%) who developed SIRS ( $p=0.264)$. Sepsis was observed in 2 patients in both groups $(p=0.826)$. Prolonged duration of surgery in ceftriaxone group and renal pelvis urine culture positivity in cefazoline group were found to be statistically significant in patients who developed SIRS ( $p=0.02, p=0.015$, respectively).

Conclusion: There was no significant difference between two groups in terms of SIRS and sepsis following PCNL. Therefore, cefazoline, which has a narrower antimicrobial spectrum, may be preferred for prophylaxis.

Keywords: Prospective, Percutaneous nephrolithotomy, Antibiotic prophylaxis, Systemic Inflammatory Response syndrome, Sepsis

Öz

Amaç: Bu çalışmanın amacı perkütan nefrolitotomi (PNL) ameliyatı olan hastaların seftriakson ve sefazolin antibiyotik profilaksisi ile Sistemik Enflamatuvar Yanıt sendromu (SiYS) ve ürosepsis komplikasyonlarının görülme sıklığının karşılaştırılmasıdır.

Gereç ve Yöntem: Hastanemizde Haziran 2015 ve Ekim 2015 tarihleri arasında PNL yapılan hastalar prospektif olarak seftriakson (30 hasta) ve sefazolin (32 hasta) antibiyotikleri kullanımı açısından randomize edilerek çalışmaya dahil edildi. SiYYS açısından riskli hastalar çalışma dışı bırakıldı. Tüm hastalardan intraoperatif renal pelvis idrar ve taş kültürleri alındı. Cerrahi sonrası ateş gelişen hastaların klinik ve laboratuvar sonuçları not edildi. İki grup arasındaki SiYS ve ürosepsis oranları karşılaştırıldı.

Bulgular: Seftriakson grubunda $7(\% 23,3)$, sefazolin grubunda ise 4 hastada $(\% 12,5)$ SiYS gelişti $(p=0,264)$. Her iki grupta da sepsis 2 'şer hastada gözlendi $(p=0,826)$. Seftriakson grubunda uzamış cerrahi süresi, sefazolin grubunda ise renal pelvisten alınan idrar kültürü pozitifliği siYS gelişen
\end{abstract}

Correspondence: Muhammet Irfan Dönmez MD, Konya Training and Research Hospital, Clinic of Urology, Konya, Turkiye

Phone: +90 5335717298 E-mail: m_irfan83@yahoo.com ORCID-ID: orcid.org/0000-0002-2828-7942

Received: 28.11.2018

Accepted: 03.12 .2018

Cite this article as: Taken K, Așı A, Eryılmaz R, Aslan R, Dönmez Mi, Güneş M. Comparison of Ceftriaxone and Cefazolin Sodium Antibiotic Prophylaxis in

Terms of SIRS/Urosepsis Rates in Patients Undergoing Percutaneous Nephrolithotomy. J Urol Surg 2019;6(2):111-117.

๑Copyright 2019 by the Association of Urological Surgery / Journal of Urological Surgery published by Galenos Publishing House. 
hastalarda istatistiksel olarak anlamlı oranda farklı bulundu ( $p$ değerleri sırasyla, $p=0,02, p=0,015$ ).

Sonuç: Seftriakson ve sefazolin grupları arasında PNL sonrası SiYS ve ürosepsis komplikasyonları arasında fark bulunmadı. Sonuç olarak daha dar anti-mikrobiyal spektruma sahip olan sefazolin sodyumun kullanılması makul gibi gözükmektedir.

Anahtar Kelimeler: Prospektif, Perkütan nefrolitotomi, Antibiyotik profilaksisi, Sistemik enflamatuvar yanıt, Sepsis

\section{Introduction}

Percutaneous nephrolithotomy (PCNL) is the preferred method for removal of renal calculi in patients with large or complex stone burden $(1,2)$. However, some perioperative and postoperative complications may develop (3). Fever and bleeding are the most common complications, while sepsis is a rare complication following PCNL (4). Sepsis has been reported to have an incidence of 9.8-37\%, while severe sepsis and septic shock occur in $0.3-4.7 \%$, with an increased risk of mortality $(4,5,6)$.

In general, administration of prophylactic antibiotics prior to surgery is performed according to the type of surgery. Inappropriate antibiotics or excessive use of broad-spectrum antibiotics (e.g. $3^{\text {rd }}$ generation cephalosporins, carbapenems or quinolones) in daily practice might be blamed for the development of bacterial resistance and increased risk of nosocomial infections. Instead of relying on empirical antibiotic regimens, it has been recommended to obtain urine samples from renal pelvis and stone cultures to guide the treatment in patients undergoing surgery for renal stones $(6,7,8)$.

The aim of this prospective study is to compare SIRS and sepsis rates after administration of two commonly used antibiotics: ceftriaxone (third generation cephalosporin) and cefazolin sodium (first generation cephalosporin) for the antibiotic prophylaxis in PCNL. Furthermore, parameters that would predict sepsis and SIRS rates are evaluated.

\section{Materials and Methods}

The study was conducted between June 2015 and October 2015, with the approval of the local ethics committee (dated on 21/06/2015, law no: 06). Informed consent was obtained from all patients prior to surgery.

Patients with renal stones $>2 \mathrm{~cm}$ and obstructing renal stones or progressive hydronephrosis or presented with renal colic were included. Exclusion criteria included fever prior to PCNL, diabetes mellitus (DM), hypertension, chronic obstructive pulmonary disease (COPD), coronary artery disease, patients who were immune compromised or received immunosuppressive therapy, history of any antibiotic treatment in the last 1 month, bilateral PCNL, preoperative urine culture positivity and $>70$ years of age. Block randomization was used for this study.
Location and size of the stones were determined either with intravenous urography or unenhanced computed tomography (CT). The surface areas of the stones were obtained by unenhanced $\mathrm{CT}$, by multiplying the longest diameter of the stone and the diameter perpendicular to this, and then multiplying the afore-mentioned result by $\pi \times 0.25$. In the presence of multiple stones, surface area for each stone was calculated separately, and the total stone burden was noted. Obstruction that led to grade 1 and 2 (as per Society for Fetal Urology grading system) hydronephrosis were assessed as mild obstruction, where those leading to grade 3 and 4 (as per Society for Fetal Urology grading system) were assessed as severe (9).

Patients were randomly divided into 2 groups regarding antibiotic prophylaxis: ceftriaxone or cefazoline sodium. Antibiotic prophylaxis was administered 30 minutes before the induction of anesthesia. Dose was $1 \mathrm{gr}$ i.v. for both antibiotics and additional dose was administered in cases with a longer than 2 hours of duration in the cefazoline sodium group. Antibiotic was continued at a daily dose of $2 \times 1 \mathrm{gr}$ i.v. till the nephrostomy was removed.

All of the patients underwent surgery following the standard premedication under intratracheal general anesthesia. PCNL was performed in standard prone technique, using balloon dilator of up to $30 \mathrm{Fr}$ and an Amplatz sheath. Povidone-iodine (10\%) was applied in all patients for skin disinfection. After percutaneous access was obtained, urine cultures from renal pelvis were collected from all patients. The threshold of positivity of urine culture was accepted $10^{5} \mathrm{CFU} / \mathrm{mL}$ in all urine samples.

As eluent, 0.9\% saline was used for irrigation and a Y-TUR kit with a pump that would provide continuous irrigation (Bıçakçılar ${ }^{\circledR}$, arthroscopy set-with puar, Turkiye) was connected to the nephroscope (Karl Storz ${ }^{\circledR}$, Germany). The stones were divided into small pieces using the pneumatic lithotripter (ELMED ${ }^{\circledR}$ AŞ, Turkiye) and extracted. The extracted stones were crushed on the surgical table and then placed into sterile Eppendorf tubes of $1 \mathrm{~mL}$ containing Triptic soy broth (Merck ${ }^{\circledR}$, Germany) for stone culture. Furthermore, one sample stone of minimum $50 \mathrm{mcg}$ was placed into a $5 \mathrm{~mL}$ syringe for assessment of stone analysis by biochemistry. The tubes for culture were incubated in the incubator and kept at $37{ }^{\circ} \mathrm{C}$ (Nüve ${ }^{\circledR}$, Turkiye) for 18-24 hours. At the end of incubation, the tubes were mixed in vortex (Nüve ${ }^{\circledR}$, Turkiye) for 10-20 seconds. The liquid in the tubes was spread onto blood agar (RTA ${ }^{\circledR}$, Turkiye) and eosin methylene blue agar (RTA ${ }^{\circledR}$, Turkiye) solid media with the 
help of a round-tipped applicator, placing a single colony each time. At the end of the incubation period, morphologies of the colonies in the positive cultures, their hemolysis characteristics and Gram staining characteristics were evaluated and required tests for identification were planned.

A $12 \mathrm{~F}$ nephrostomy catheter was placed in all patients after surgery. If any residual stones were present, which might cause extravasation or obstruction, a 26/4.7 Double J (DJ) catheter (Bay care ${ }^{\circledR}$ ureteral stent) was inserted in the lithotomy position.

Information about early postoperative complications such as bleeding, extravasation, infection and fever were recorded under the scope of the study. The complications were classified according to the modified Clavien classification system (10).

After surgery, patients were monitored closely in the first 48 hours. Urine and blood culture samples were obtained from all of the patients who developed fever in the postoperative period. SIRS was defined as the development of two of four criteria, namely body temperature $<36^{\circ} \mathrm{C}$ or $>38^{\circ} \mathrm{C}$, heart rate $>90$ beats/ $\mathrm{min}$, respiratory rate $>20 / \mathrm{min}$ and white cell count $>12.000 /$ $\mathrm{mL}$ or $<4.000 / \mathrm{mL}$ (11). Sepsis was defined as the presence of a source of infection together with SIRS (11). Patients were adequately hydrated, treated with analgesics, and other causes for SIRS. Situation such as phlebitis or atelectasis were ruled out by physical examination and chest X-ray. Results of serum $C$ reactive protein (CRP), perioperative/postoperative urine, stone, renal pelvis urine and blood cultures were evaluated and treatment was arranged accordingly.

Patients were evaluated for residual stone in the postoperative period with X-ray or ultrasonography. CT was performed when necessary. Residual stones of $\leq 4 \mathrm{~mm}$ were considered as clinically insignificant residuals fragments.

In our study, the relationship between SIRS/sepsis and duration of surgery, stone burden, duration of nephrostomy, placement of DJ catheter, presence of severe obstruction, residual stone, renal pelvis urine and stone cultures results were analyzed.

\section{Statistical Analysis}

Descriptive statistics for continuous variables were expressed as average, standard deviation, minimum and maximum values; and for categorical variables, numbers and percentages were used. One-way ANOVA test was used for the comparison of the parametric groups in terms of continuous variables, and MannWhitney $U$ test was used for the non-parametric groups. Chisquare test was used for determining the relationship between groups and the categorical variables. The SPSS (ver.20) statistical package was used, and a $p$ value of $<0.05$ was accepted as statistically significant.

\section{Results}

A total of 62 patients were enrolled in the study. There were 40 male (64.6\%) and 22 (35.4\%) female patients. The average age of patients in the ceftriaxone group was $46.87 \pm 17.68$ (range 1870) whereas it was $37.06 \pm 15.56$ (range 18-69) in the cefazoline sodium group. There was no statistically significant difference in patients in terms of age and gender ( $p>0.05)$. The demographic and the clinical data of the patients were listed in (Table 1). No statistical significant difference was found between groups in terms of duration of nephrostomy, number of accesses, degree of hydronephrosis, type of surgery, mean stone burden, stone free rate and complications (bleeding, extravasation and SIRS) ( $p>0.05$, for all).

According to the modified Clavien classification, grade 1 complications were observed in 15 patients (24\%), grade 2 in 17 patients $(27.4 \%)$, grade $3 a$ in 3 patients $(4.8 \%)$, and grade $4 \mathrm{~b}$ in 4 patients $(6.4 \%)$, respectively. No mortality (grade 5 ) was observed.

There were 7 patients in the ceftriaxone group (23.3\%) while there were 4 patients in the cefazoline sodium group (12.5\%) who developed SIRS $(p=0.264)$. Sepsis was observed in 2 patients in both groups $(p=0.826)$. Two of 7 patients in the

Table 1. Demographic and clinical data of the study patients

\begin{tabular}{|c|c|c|}
\hline Mean Age & $41.81 \pm 17.21(18-70)$ & \\
\hline \multirow{2}{*}{ Gender $(n, \%)$} & Male & $40(64.6 \%)$ \\
\hline & Female & $22(35.4 \%)$ \\
\hline \multirow{3}{*}{ Type of Surgery (\%) } & Primary & 82.3 \\
\hline & Secondary & 12.9 \\
\hline & Tertiary & 4.8 \\
\hline Mean stone burden $\left(\mathrm{cm}^{2}\right)$ & $7.16(1.9-21.1)$ & \\
\hline \multirow{2}{*}{$\begin{array}{l}\text { Degree of hydronephrosis } \\
\text { (as per SFU classification) } \\
(\%)\end{array}$} & Grade 3-4 & 17.7 \\
\hline & Grade 1-2 & 82.3 \\
\hline \multirow{2}{*}{ Number of access (\%) } & Single & 96.8 \\
\hline & Multiple & 3.2 \\
\hline $\begin{array}{l}\text { Duration of surgery } \\
\text { (minimum) }\end{array}$ & $83.2(30-170)$ & \\
\hline \multirow{3}{*}{ Stone status (\%) } & Complete stone free & 72.6 \\
\hline & $\begin{array}{l}\text { Clinically insignificant } \\
\text { residue }\end{array}$ & 11.3 \\
\hline & $\begin{array}{l}\text { Clinically significant } \\
\text { residue }\end{array}$ & 16.1 \\
\hline $\begin{array}{l}\text { Duration of nephrostomy } \\
\text { (days) }\end{array}$ & $2.11(1-4)$ & \\
\hline \multirow{3}{*}{ Complication (\%) } & Bleeding & 9.6 \\
\hline & Extravasation & 6.4 \\
\hline & SIRS & 16.1 \\
\hline
\end{tabular}

SFU: Summary fault unit, SIRS: Systemic Inflammatory Response syndrome 
ceftriaxone group with SIRS positivity (28.5\%) showed growth in renal pelvis urine culture. On the other hand, 2 of 4 patients with SIRS positivity (50\%) observed renal pelvis urine culture positivity in the cefazoline sodium group. All of cultures were noted to have resistance to ceftriaxone and cefazoline sodium, therefore carbapenems were initiated.

In our study, stone culture positivity was observed in 11 patients. SIRS and renal pelvis urine culture positivity were seen in 3 of these patients (27.3\%). Stone culture positivity was not associated with SIRS development in both groups ( $p=0.087$ vs $\mathrm{p}=0.847$ ).

No association was found between DJ stent placement, residual fragments, bleeding, and the absence of extravasation in terms of SIRS development ( $p>0.05$, for all). Additionally, postoperative CRP levels were found to be statistically higher in SIRS $(+)$ patients $(p=0.008)$.

Increased duration of surgery in the ceftriaxone group ( $p=0.02)$, and renal pelvis urine culture positivity in the cefazoline group were found to be associated with SIRS ( $p=0.015)$. The comparisons of parameters related with SIRS in both groups were presented in (Table 2).

The most commonly isolated microorganisms in stone culture samples were $E$. coli (31.2\%), and Coagulase-negative Staphylococcus (CNS) family (31.2\%). Most frequently isolated microorganism from the renal pelvis urine culture samples was CNS (38.4\%). However, CNS was not found to predict urosepsis. Moreover, stone cultures were positive for Enterococcus,
Pseudomonas pseudoalcaligenes and Candida spp.; 12.5\%, $6.2 \%$ and $6.2 \%$, respectively.

In terms of stone analysis, calcium stones were detected in 28 patients (45.1\%), uric acid stones in 13 patients (20\%), and calcium + uric acid stones in 9 patients (14.5\%).

\section{Discussion}

The success of PCNL ranges between $72-98 \%$ in published large series $(12,13)$. In our study, in accordance with the literature, the success rate of PCNL was found to be $83.9 \%$.

The most common complications of PCNL were reported as fever (21-32.1\%), hemorrhage requiring blood transfusion (11.2$17.5 \%)$ and extravasation (7.2\%). Septic shock (0.3-4.7\%), colon injuries (0.2-4.8\%) and pleural injury (0-3.1\%) were reported as rare major complications $(4,14,15)$. Most commonly reported complications were grade 1 and 2 complications according to the modified Clavien grading system (16). Consistent with the literature, our complications were mostly grade 1 and 2 .

SIRS is an important predictor for urosepsis; however, each SIRS case cannot be called urosepsis without showing the source of infection. Renal pelvis urine culture and stone cultures have been shown to have better predictive value for urosepsis than midstream urine culture $(5,17,18)$. Although preoperative midstream urine culture of the patient was sterile, systemic infections have been reported. A previous study has determined positive renal pelvis culture in $10.1 \%$ of the cases

Table 2. Parameters and their relationship with Systemic Inflammatory Response syndrome in both groups

\begin{tabular}{|c|c|c|c|c|c|c|}
\hline & \multicolumn{3}{|c|}{ Cefazolin sodium } & \multicolumn{3}{|l|}{ Ceftriaxone } \\
\hline & $\begin{array}{l}\text { SIRS (-) } \\
(n=28)\end{array}$ & $\begin{array}{l}\text { SIRS (+) } \\
(n=4)\end{array}$ & $\mathbf{p}$ & $\begin{array}{l}\text { SIRS (-) } \\
(n=23)\end{array}$ & $\begin{array}{l}\text { SIRS (+) } \\
(n=7)\end{array}$ & $\mathbf{p}$ \\
\hline Duration of surgery (mins) & 84.86 & 93.75 & 0.344 & 77.17 & 90.71 & $0.02^{*}$ \\
\hline Stone burden $\left(\mathrm{cm}^{2}\right)$ & 7.00 & 5.10 & 0.669 & 6.96 & 9.69 & 0.624 \\
\hline Duration of nephrostomy (days) & 2.20 & 1.75 & 0.082 & 2.11 & 2.00 & 0.720 \\
\hline Placement of DJ stent (n) & $\begin{array}{l}8 \\
(28.5 \%)\end{array}$ & $\begin{array}{l}3 \\
(75 \%)\end{array}$ & 0.067 & $10(43.4 \%)$ & $\begin{array}{l}2 \\
(28.5 \%)\end{array}$ & 0.481 \\
\hline Severe obstruction (n) & $\begin{array}{l}3 \\
(10.7 \%)\end{array}$ & $\begin{array}{l}0 \\
(0.0 \%) \\
\end{array}$ & 0.492 & $\begin{array}{l}8 \\
(34.7 \%)\end{array}$ & $\begin{array}{l}0 \\
(0.0 \%) \\
\end{array}$ & 0.68 \\
\hline Residual stone (n) & $\begin{array}{l}6 \\
(75.0 \%)\end{array}$ & $\begin{array}{l}2 \\
(25.0 \%) \\
\end{array}$ & 0.217 & $\begin{array}{l}4 \\
(66.7 \%) \\
\end{array}$ & $\begin{array}{l}2 \\
(33.3 \%) \\
\end{array}$ & 0.517 \\
\hline Renal pelvis urine culture positivity (n) & $\begin{array}{l}2 \\
(7.1 \%) \\
\end{array}$ & $\begin{array}{l}2 \\
(50 \%) \\
\end{array}$ & $0.015^{* *}$ & $\begin{array}{l}2 \\
(8.6 \%) \\
\end{array}$ & $\begin{array}{l}2 \\
(28.5 \%) \\
\end{array}$ & 0.176 \\
\hline Stone culture positivity & $\begin{array}{l}2 \\
(7.1 \%)\end{array}$ & $\begin{array}{l}2 \\
(50.0 \%)\end{array}$ & 0.087 & $\begin{array}{l}1 \\
(4.3 \%)\end{array}$ & $\begin{array}{l}6 \\
(85.7 \%)\end{array}$ & 0.847 \\
\hline
\end{tabular}

SIRS: Systemic Inflammatory Response syndrome, DJ: Double J, *: $p=0.02{ }_{1}{ }^{* *}: p=0.015$ 
with preoperative sterile urine culture (19). In their prospective study with 98 patients, Mariappan et al. (7) reported stone culture positivity in both of the patients who developed septic shock, infected stone culture in 4 of 7 patients and infected renal pelvis urine culture in 1 patient, in the treatment group that developed SIRS. In our study, despite a sterile midstream culture, renal pelvis urine culture positivity was $12.9 \%$, and stone culture positivity was $17.7 \%$. SIRS was determined in $50 \%$ of the patients with positive renal pelvis urine culture, and in $27.2 \%$ of the patients with positive stone culture.

Risk factors that facilitate the development of sepsis include underlying chronic diseases (DM, heart failure, chronic renal failure, COPD), AIDS, cytotoxic and immunosuppressive drug use, conditions that may cause immunosuppression such as malignancy and alcoholism, history of urinary tract infection, urinary tract anomalies, previous urinary tract catheterization and advanced age $(20,21)$. These patients were excluded from our study in order to reduce bias in a relatively small cohort.

The most common complications of sepsis are shock and organ failure. Incidence of severe sepsis and septic shock is as low as $0.3-4.7 \%$ in PCNL or endoscopic procedures. However, it is a serious life-threatening complication and the mortality rate is up to $66 \%(4,14,20)$. The organs/systems that carry the maximum risk for dysfunction or failure are the cardiovascular system, lungs, kidneys, liver, pancreas, gastrointestinal system, coagulation system and the CNS (22). In our study, we observed 4 patients who developed sepsis with 2 patients in each group. Of those, respiratory distress developed in 1 , and elevation of creatinine, which improved during follow-up, was observed in 2. No mortality was observed in any patients in our study.

Despite no proven benefit of prophylactic antibiotic application in the presence of sterile urine in PCNL, the general trend is towards a short-term use of antibiotics. This is usually in the form of beginning before surgery and continuing for 48 hours. However, in cases with sterile pre operative urine culture and with no predictive risk factors for upper tract infections, there are studies reporting that single use of preoperative antibiotic administration would be sufficient $(15,19)$. As those reports may represent a different geographic antibiotic resistance pattern and local bacterial resistance to antibiotics is a major problem in our country, our clinical approach is to keep the patient on i.v antibiotics until the nephrostomy tube is withdrawn.

Renal pelvis urine culture positivity, stone culture positivity, stone burden, duration of nephrostomy, using multiple accesses and increased duration of surgery were reported as the predictors of SIRS development $(5,15,19)$. We found prolonged operation time in ceftriaxone group and renal pelvis urine culture positivity in cefazoline group is associated with development of SIRS.
Drugs recommended for prophylaxis include cephalosporins (AUA: $1^{\text {st }}-2^{\text {nd }}$ generation, EAU: $2^{\text {nd }}-3^{\text {rd }}$ generation), trimethoprim \pm sulfamethoxazole, fluoroquinolones, aminoglycosides and aminopenicillin. The duration of preoperative antibiotic treatment as well as the exact timing of surgery remains controversial (23). The number of randomized controlled studies that report rates of infection according to the antibiotics that are used in endoscopic surgical procedures such as PCNL is still insufficient. Thus, we don't have a clear idea of which antibiotic should be chosen for prophylaxis in cases where the genitourinary system is involved such as PCNL. The lack of a specific algorithm and development of different prophylaxis insights of the clinics, unfortunately lead to development of resistance to antibiotics. There has been a similar prospective and randomized study in which the authors compared ciprofloxacin and ceftriaxone. However, no significant difference was observed between ciprofloxacin and ceftriaxone in terms of SIRS (15). They reported the SIRS incidence after PCNL as $15.5 \%$ for the ciprofloxacin group and 8.8\% for the ceftriaxone group. In our study, we compared $1^{\text {st }}$ and $3^{\text {rd }}$ generation cefalosporins, which have different antimicrobial spectrums. Our aim was to compare cefazoline sodium, which has a narrower spectrum, and is more effective on the skin flora and Gram-positive organisms, such as CNS, with ceftriaxone, which is more commonly preferred but has a broader spectrum. In our study, SIRS developed in a total of 4 patients $(12.5 \%)$ in the cefazoline group, whereas a total of 7 patients (23.3\%) in the ceftriaxone group. No statistically significant difference was observed between groups in terms of SIRS and sepsis. As the controlled randomized studies conducted with larger numbers increase, we believe that antibiotic prophylaxis for this particular procedure may be standardized.

E.coli is the most common organism isolated in PCNL or endoscopic procedures, as well as other microorganisms such as Proteus, Klebsiella, Enterobacter and Pseudomonas $(24,25)$. In stone cultures; Gram (+) bacteria such as Enterococcus and Staphylococcus were reported (25). In our study, CNS was the most common in all culture samples (stone + renal pelvis) followed by E. coli Additionally, E. coli with a rate of 31.2\% and CNS with a rate of $31.2 \%$ were found in stone cultures. In a recent report of 11 patients who developed sepsis; 7 were positive for Gram-positive organisms, 2 for Candida, while only 1 for E. coli and Klebsiella (25). The authors suggested that if sepsis were suspected, the initial antibiotic regimen should be an antibiotic directed against Gram-positive bacteria, such as Vancomycin or a Beta-lactam, and one to treat Gram-negative bacteria such as Gentamicin or Cefipime. Although Gram (+) bacteria were isolated in large ratios in the cultures in our study, similar antibiotic sensitivity rates were determined for cefazolin sodium and ceftriaxone. Imipenem was initiated in one of the patients who had developed sepsis in the cefazoline sodium 
group, ertapenem in another, and furthermore, ertapenem was started in one of the patients in the ceftriaxone group who had developed sepsis, and piperacillin + tazobactam in the other. In all of these patients, similar resistance rates to ceftriaxone and cefazoline sodium were observed in the culture antibiograms.

\section{Study Limitations}

Main limitation of our study is that no microscopic analysis of renal pelvis urine was performed. We suggest microscopic analysis of renal pelvis urine should be performed in future studies that facilitate earlier diagnosis of infectious complications.

\section{Conclusion}

In order to reduce the risk of microbial resistance, appropriate antibiotic prophylaxis should be chosen based on the intraoperative stone and renal pelvis urine culture results. In our study, there was no significant difference between two groups in terms of SIRS and sepsis following PCNL. Therefore, cefazoline, which has a narrower antimicrobial spectrum, may be preferred for prophylaxis.

\section{Ethics}

Ethics Committee Approval: All studies have been approved by the appropriate ethics committee and have, therefore, been performed in accordance with the ethical standards laid down in the 1964 Declaration of Helsinki and its later amendments.

Informed Consent: All persons gave their informed consent prior to their inclusion in the study.

Peer-review: Externally peer-reviewed.

\section{Authorship Contributions}

Consept: KT., AA., RE., RA., MG., Design: KT., AA., RE., RA., MG., Data Collection and/or Processing: KT., AA., RE., RA., MG., Analysis and/or Interpretation: KT., AA., RE., RA., MiD., MG., Literature Research: KT., AA., RE., RA., MID., MG., Writing: KT., MiD.

Conflict of Interest: No conflict of Interest was declared by the authors.

Financial Disclosure: The authors declared that this study received no financial support.

\section{References}

1. de la Rosette J, Assimos D, Desai M, Gutierrez J, Lingeman J, Scarpa R, Tefekli A, Group CPS. The Clinical Research Office of the Endourological Society Percutaneous Nephrolithotomy Global Study: indications, complications, and outcomes in 5803 patients. J Endourol 2011;25:11-17.

2. Osman $M$, Wendt-Nordahl $G$, Heger $K$, Michel MS, Alken $P$, Knoll $T$. Percutaneous nephrolithotomy with ultrasonography-guided renal access: experience from over 300 cases. BJU Int 2005;96:875-878.
3. Draga RO, KokET, Sorel MR, Bosch RJ, LockTM. Percutaneous nephrolithotomy: factors associated with fever after the first postoperative day and systemic inflammatory response syndrome. J Endourol 2009;23:921-927.

4. Michel MS, Trojan L, Rassweiler JJ. Complications in percutaneous nephrolithotomy. Eur Urol 2007;51:899-906; discussion 906.

5. Shoshany 0, Margel D, Finz C, Ben-Yehuda O, Livne PM, Holand R, Lifshitz D. Percutaneous nephrolithotomy for infection stones: what is the risk for postoperative sepsis? A retrospective cohort study. Urolithiasis 2015;43:237242.

6. Korets R, Graversen JA, Kates M, Mues AC, Gupta M. Post-percutaneous nephrolithotomy systemic inflammatory response: a prospective analysis of preoperative urine, renal pelvic urine and stone cultures. J Urol 2011;186:1899-1903.

7. Mariappan P, Smith G, Bariol SV, Moussa SA, Tolley DA. Stone and pelvic urine culture and sensitivity are better than bladder urine as predictors of urosepsis following percutaneous nephrolithotomy: a prospective clinical study. J Urol 2005;173:1610-1614.

8. Koras $\mathrm{O}$, Bozkurt IH, Yonguc T, Degirmenci T, Arslan B, Gunlusoy B, Aydogdu 0 , Minareci S. Risk factors for postoperative infectious complications following percutaneous nephrolithotomy: a prospective clinical study. Urolithiasis 2015;43:55-60.

9. Nguyen $\mathrm{HT}$, Herndon $\mathrm{CD}$, Cooper $\mathrm{C}$, Gatti J, Kirsch $\mathrm{A}$, Kokorowski $\mathrm{P}$, Lee R, Perez-Brayfield M, Metcalfe P, Yerkes E, Cendron M, Campbell JB. The Society for Fetal Urology consensus statement on the evaluation and management of antenatal hydronephrosis. J Pediatr Urol 2010;6:212-231.

10. Dindo D, Clavien PA. What is a surgical complication? World J Surg 2008;32:939-941.

11. Levy MM, Fink MP, Marshall JC, Abraham E, Angus D, Cook D, Cohen J, Opal SM, Vincent JL, Ramsay G, Sccm/Esicm/Accp/Ats/Sis. 2001 SCCM/ESICM/ ACCP/ATS/SIS International Sepsis Definitions Conference. Crit Care Med 2003;31:1250-1256

12. Opondo D, Tefekli A, Esen $T$, Labate G, Sangam K, De Lisa A, Shah $H$, de la Rosette J, group CPs. Impact of case volumes on the outcomes of percutaneous nephrolithotomy. Eur Urol 2012;62:1181-1187.

13. Goldwasser B, Weinerth JL, Carson CC, Dunnick NR. Factors affecting the success rate of percutaneous nephrolithotripsy and the incidence of retained fragments. J Urol 1986;136:358-360

14. O'Keeffe NK, Mortimer AJ, Sambrook PA, Rao PN. Severe sepsis following percutaneous or endoscopic procedures for urinary tract stones. Br J Urol 1993;72:277-283.

15. Demirtas A, Yildirim YE, Sofikerim M, Kaya EG, Akinsal EC, Tombul ST, Ekmekcioglu 0, Gulmez I. Comparison of infection and urosepsis rates of ciprofloxacin and ceftriaxone prophylaxis before percutaneous nephrolithotomy: a prospective and randomised study. Scientific World Journal 2012;2012:916381.

16. Shin TS, Cho HJ, Hong SH, Lee JY, Kim SW, Hwang TK. Complications of Percutaneous Nephrolithotomy Classified by the Modified Clavien Grading System: A Single Center's Experience over 16 Years. Korean J Urol 2011;52:769-775.

17. Cadeddu JA, Chen R, Bishoff J, Micali S, Kumar A, Moore RG, Kavoussi LR. Clinical significance of fever after percutaneous nephrolithotomy. Urology 1998;52:48-50.

18. Bratell S, Brorson JE, Grenabo L, Hedelin H, Pettersson S. The bacteriology of operated renal stones. Eur Urol 1990;17:58-61.

19. Dogan HS, Guliyev F, Cetinkaya YS, Sofikerim M, Ozden E, Sahin A. Importance of microbiological evaluation in management of infectious complications following percutaneous nephrolithotomy. Int Urol Nephrol 2007;39:737-742.

20. Gutierrez J, Smith $A$, Geavlete $P$, Shah $H$, Kural AR, de Sio M, Amon Sesmero JH, Hoznek A, de la Rosette J, Group CPS. Urinary tract infections 
and post-operative fever in percutaneous nephrolithotomy. World J Urol 2013;31:1135-1140.

21. Hsiao CY, Yang HY, Chang CH, Lin HL, Wu CY, Hsiao MC, Hung PH, Liu SH, Weng $\mathrm{CH}$, Lee CC, Yen TH, Chen YC, Wu TC. Risk Factors for Development of Septic Shock in Patients with Urinary Tract Infection. Biomed Res Int 2015;2015:717094.

22. Martin GS, Mannino DM, Eaton S, Moss M. The epidemiology of sepsis in the United States from 1979 through 2000. N Engl J Med 2003;348:1546-1554.

23. Mariappan P, Smith G, Moussa SA, Tolley DA. One week of ciprofloxacin before percutaneous nephrolithotomy significantly reduces upper tract infection and urosepsis: a prospective controlled study. BJU Int 2006;98:1075-1079.

24. Margel D, Ehrlich Y, Brown N, Lask D, Livne PM, Lifshitz DA. Clinical implication of routine stone culture in percutaneous nephrolithotomy--a prospective study. Urology 2006;67:26-29.

25. Eswara JR, Shariftabrizi A, Sacco D. Positive stone culture is associated with a higher rate of sepsis after endourological procedures. Urolithiasis 2013;41:411-414. 